\title{
Virus SARS-CoV-2 ¿Qué se sabe al momento?
}

\section{SARS-CoV-2 Virus. What is currently known?}

\author{
Patricia Saltigeral-Simental, Ximena León-Lara
}

\begin{abstract}
Resumen
El virus SARS-CoV-2 se identificó por primera vez en la ciudad de Wuhan, China, a finales de 2019. Desde entonces, la enfermedad producida por este nuevo coronavirus COVID-19, representa una amenaza creciente para la salud humana. EI SARS-CoV-2 es un virus de ARN monocatenario envuelto. La secuenciación completa de su genoma ha permitido clasificarlo en el género Betacoronavirus, de la subfamilia Coronavirinae. La similitud genómica con coronavirus derivados de murciélagos y pangolines malayos sugiere a los murciélagos como el reservorio natural principal y a los pangolines como el huésped intermediario. La glicoproteína S viral es un objetivo clave para el desarrollo de vacunas, de blancos terapéuticos y de pruebas diagnósticas. Esta proteína desempeña un papel decisivo en la unión y entrada a la célula blanco y determina el tropismo del virus por el huésped.
\end{abstract}

PALABRAS CLAVE: SARS-CoV-2; coronavirus COVID-19; reservorio; tropismo viral; glicoproteína; vacunas terapéuticas; prueba diagnóstica.

\section{Abstract}

The SARS-CoV-2 was first identified in the city of Wuhan, China, in late 2019. Since then, the disease caused by this new coronavirus, COVID-19, represents a growing threat to human health. SARS-CoV-2 is an enveloped single-stranded RNA virus classified in the subfamily Coronavirinae, genus Betacoronavirus. The homology of genomes suggests that bats might be the original host of the virus, and pangolins the intermediate host. The viral glycoprotein $\mathrm{S}$ is a crucial target for the development of vaccines, therapeutic targets, and diagnostic tests. This protein facilitates viral entry into target cells and determines host tropism.

KEYWORDS: SARS-CoV 2; coronavirus COVID-19; Bats; Viral Tropism; Glycoprotein; Vaccines therapeutic; Diagnostic test.
Adscrita del Servicio de Infectología.

Instituto Nacional de Pediatría, Ciudad de México.

Recibido: 14 de mayo 2020

Aceptado: 5 de junio 2020

Correspondencia

Patricia Saltigeral-Simental

drapatysaltigerals@hotmail.com

Este artículo debe citarse como Saltigeral-Simental P, León-Lara X. Virus SARS-CoV2 ¿Qué se sabe al momento? Acta Pediatr Méx 2020; (Supl 1):S3-S7.

\section{Clasificación del SARS-CoV-2}

La familia Coronaviridae, perteneciente al orden Nidovirales, es un grupo amplio de virus capaces de infectar y producir enfermedad respiratoria o gastrointestinal en diferentes especies de aves y mamíferos: cerdos, murciélagos, roedores, camellos. ${ }^{1,2}$ Los miembros de esta familia se caracterizan por sus proteínas en forma de espiga, que se proyectan desde su superficie, al ser observados por microscopia electrónica. ${ }^{2}$

La familia Coronaviridae se divide, a su vez, en dos subfamilias: Coronavirinae y Torovirinae, y los miembros de la subfamilia Coronavirinae se subdividen en cuatro géneros principales: alfa-, beta-, gamma- y deltacoronavirus, basado en comparaciones del genoma completo. ${ }^{1,2}$ Hasta la fecha se han identificado siete coronavirus (CoV) que han cruzado la barrera entre especies produciendo enfermedad en humanos, causando desde infección respiratoria leve hasta enfermedades más graves, como el síndrome respiratorio agudo grave. ${ }^{1}$ Estos coronavirus humanos $(\mathrm{HCoV})$ pertenecen a los géneros alfacoronavirus y betacoronavirus, y cuatro de ellos (HCoV-229E, HCoV-NL63, HCoV-OC43 y HCoV-HKU1) circulan globalmente en la 
población; contribuyen, aproximadamente, con un tercio de las infecciones por resfriado común en humanos. ${ }^{1}$

El brote más reciente de enfermedad por coronavirus se originó en la ciudad de Wuhan, la capital de la provincia china de Hubei, en diciembre de 2019.3,4 Actualmente representa una amenaza potencial creciente para la salud humana por la falta de inmunidad previa para este virus en la población, y por ser un virus altamente transmisible, con un número reproductivo básico R0 entre 2.2-3.9.5

La secuenciación completa del genoma y el análisis filogénico han permitido clasificar al virus responsable de esta nueva enfermedad por coronavirus, COVID-19, como un nuevo virus dentro del género betacoronavirus, de la subfamilia Coronavirinae, junto con SARS-CoV y MERS-CoV, con quienes comparte 79 y 50\%, respectivamente, de similitud genómica. ${ }^{6,7,8}$ Inicialmente, la OMS lo denominó nuevo coronavirus 2019 (2019-nCoV) y, posteriormente, coronavirus tipo 2 del síndrome respiratorio agudo grave (SARS-CoV-2) por el Comité Internacional de Taxonomía de Virus. ${ }^{6}$

Mediante el análisis filogenético de 103 cepas de SARS-CoV-2 de China se han propuesto dos tipos diferentes de SARS-CoV-2, el tipo $L$ y el tipo $S$, basado en dos polimorfismos puntuales estrechamente vinculados en la posición 8,782 (en el gen orf1ab) y 28,144 (en el gen ORF8). ${ }^{9}$ Los tipo $\mathrm{L}$ representaron $70 \%$ de la muestra y los tipo S 30\%, que parece ser ancestral al tipo L. ${ }^{9}$ Se desconocen las implicaciones clínicas de estos hallazgos. Pareciera que el tipo $L$ tiene una tasa de transmisión más alta y se replica más rápido en la población, lo que hace que acumule más mutaciones; sin embargo, esto no se ha comprobado. ${ }^{9}$

\section{Origen del SARS-CoV-2}

El primer lugar donde se identificó el SARSCoV-2 fue en un mercado de mariscos en la ciudad de Wuhan, China, donde existe la posibilidad de transmisión de patógenos de animales salvajes a humanos. ${ }^{3,4}$ La secuencia completa de nucleótidos del SARS-CoV-2 reveló que está estrechamente relacionado con otros coronavirus similares al SARS derivados del murciélago, con $88 \%$ de similitud con bat-SLCoVZC45, 87\% con bat-SL-CoVZXC21 y $96 \%$ con bat-CoVRaTG13. ${ }^{7,8}$ La mayoría de las proteínas codificadas mostraron alta similitud en la secuencia entre el SARS-CoV-2 y los coronavirus derivados de murciélagos bat-SL-CoVZC45 y bat-SL-CoVZXC21, con excepción de la proteína de superficie $S$ y proteína $13 .{ }^{7}$ La similitud en su secuencia fue superior a $90 \%$ en cinco regiones genéticas ( $E, M, 7, N$ y 14 ), la más alta fue en el gen $E$ con $98.7 \%$ de similitud. ${ }^{7}$ Esto sugiere a los murciélagos como el principal reservorio natural de este virus, que fue trasmitido al humano quizá a través de un huésped intermediario como algún animal salvaje vendido en el mercado de mariscos de Wuhan en China. ${ }^{10}$

La ruta específica de transmisión de los reservorios naturales a los humanos sigue sin estar clara. Algunos estudios han propuesto que los pangolines malayos pueden haber proporcionado el dominio de unión al receptor del gen Spike al nuevo virus SARS-CoV-2. ${ }^{9,11-14}$ Los pangolines y los murciélagos son animales nocturnos, se alimentan de insectos y comparten nichos ecológicos, lo que hace que los pangolines sean el huésped intermediario ideal para algunos coronavirus de murciélagos. ${ }^{13,14}$ La cepa de coronavirus aislada de pangolines muestra una similitud de 99, 94, 94 y 89\% con SARS-CoV-2 en la secuencia de nucleótidos de los genes $E$, $M, N$ y $S$, respectivamente. ${ }^{14}$ Específicamente 
los sitios funcionales críticos en la proteína de superficie $\mathrm{S}$ de SARS-CoV-2 son casi idénticos a los del coronavirus en pangolines. ${ }^{12,14}$

\section{Estructura y genoma del SARS-CoV-2}

El SARS-CoV-2 es un virus esférico, envuelto Con un diámetro aproximado de 60-140 nm. ${ }^{15}$ $\mathrm{Al}$ igual que otros coronavirus es sensible a los rayos ultravioleta y al calor (Figura 1). ${ }^{16,17}$ Además, se inactiva con solventes lipídicos como éter (75\%), etanol, cloro y ácido peroxiacético. ${ }^{16}$ Cuenta con un genoma de ácido ribonucleico (ARN) monocatenario de sentido positivo, con una longitud aproximada de 30,000 nucleótidos (Figura 2). 8,9

El genoma del virus consta de seis marcos principales de lectura abierta (ORF), que son

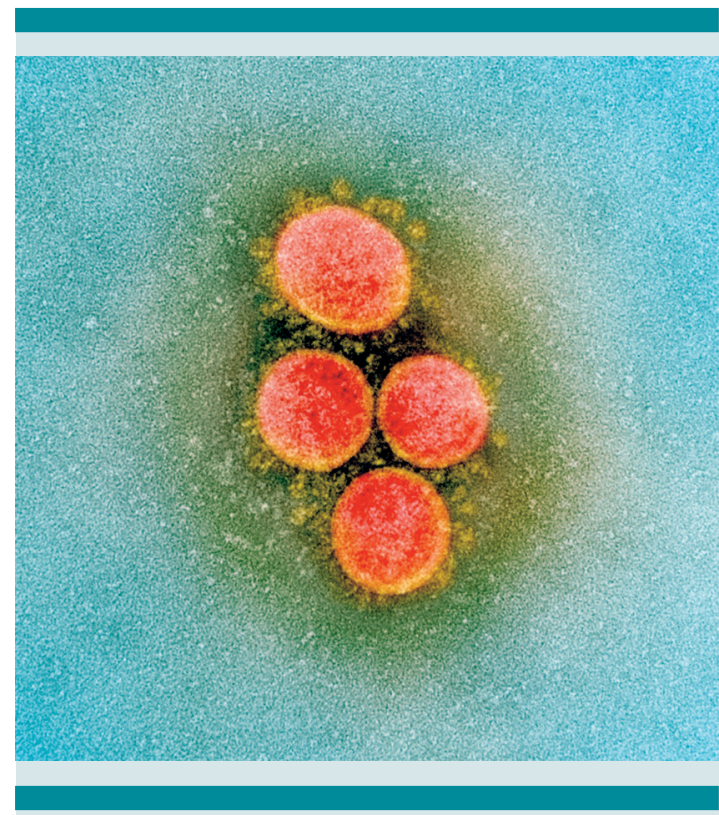

Figura 1. Micrografía electrónica de partículas virales de SARS-CoV-2, aislada de un paciente.

Imagen capturada y mejorada en color en el Centro de Investigación Integrada (IRF, de sus siglas en ingles Integrated Research Facility) del NIAID en Fort Detrick, Maryland. Crédito: NIAID17 comunes a los coronavirus y una serie de otros genes accesorios. ${ }^{8}$ El genoma codifica para 9860 aminoácidos y 27 proteínas, incluidas las de la ARN polimerasa dependiente de ARN y cuatro proteínas estructurales. ${ }^{8,16,18}$ Los ORF1a y ORF1b codifican las proteínas no estructurales. ${ }^{19}$ Las cuatro proteínas estructurales del SARS-CoV-2 incluyen la proteína de superficie (S), la proteína pequeña de la envoltura $(\mathrm{E})$, la proteína de matriz (M) y la proteína de nucleocápside $(\mathrm{N}) \cdot{ }^{18}$ Las proteínas E y M están asociadas con la envoltura viral y la proteína $\mathrm{N}$ está en el interior del virión asociada con el ARN viral. ${ }^{2}$ La proteína $\mathrm{S}$ es una glicoproteína de fusión trimérica de clase I, que se proyecta de la superficie viral. ${ }^{15,20}$ Esta proteína desempeña un papel decisivo en la unión a los receptores en la célula huésped y determina el tropismo del huésped. ${ }^{20,21}$ Por eso es un objetivo clave para vacunas, blancos terapéuticos, anticuerpos y pruebas diagnósticas. ${ }^{21}$

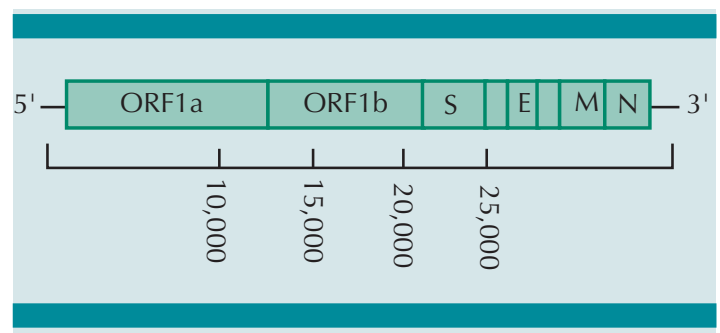

Figura 2. Representación del genoma del SARS-CoV-2. Adaptado de: Nature. 2020 Mar;579(7798):270-273.8

Se han identificado 14 mutaciones acumulativas en el gen que codifica para la proteína S. Estas mutaciones pueden conferir ventajas selectivas en la transmisión o resistencia a las intervenciones terapéuticas e, incluso, preventivas como las vacunas. ${ }^{22}$ De manera específica, la mutación en el gen Spike D614G está reemplazando a la forma original del virus (originado en Wuhan, China) en el mundo, principalmente en Europa. ${ }^{22}$ Esta mutación podría conferir resistencia a la 
respuesta protectora de los anticuerpos dirigidos a D614 en personas infectadas, haciéndolas más susceptibles a la reinfección con la nueva forma del virus, además de que podría tener consecuencias directas para la infectividad del virus y poca protección por las vacunas dirigidas a este epítopo. ${ }^{22}$

\section{Ciclo de replicación de SARS-CoV-2}

EI SARS-CoV-2 parece interactuar mediante la glucoproteína $\mathrm{S}$ trimérica con el receptor de la enzima convertidora de angiotensina 2 (ECA2), al igual que SARS-CoV. ${ }^{8,21}$ La glucoproteína $S$ trimérica del SARS-CoV-2 sufre un reordenamiento estructural para iniciar la fusión de la membrana viral e ingresar en las células humanas. ${ }^{20}$

A diferencia de SARS-CoV, el estado predominante del trímero de la glucoproteína $S$ del SARS-CoV-2 tiene uno de los tres dominios de unión al receptor rotados hacia arriba en una conformación accesible al receptor, y difiere en cinco de los seis residuos críticos de aminoácidos en el dominio de unión al receptor. ${ }^{9,20}$ Estos mismos seis residuos críticos de aminoácidos del SARS-CoV-2 son idénticos a los de cepa de coronavirus en pangolines, y sólo un residuo es similar a los de la cepa de coronavirus en murciélagos (bat-CoVRaTG13).9,11,14

Mediante un análisis estructural 3D se observó que la proteína $\mathrm{S}$ del SARS-CoV-2 tiene mayor afinidad a su receptor, que la proteína $S$ del SARS-CoV, con una unión al menos 10 veces más intensa al receptor ECA2. ${ }^{20}$ El receptor ECA2 se expresa en diferentes tejidos, principalmente en el epitelio de las vías respiratorias y neumocitos alveolares tipo 2, lo que explica la expresión clínica de la infección porque estas células pueden servir como reservorio para la invasión viral. ${ }^{21,23}$ El receptor de ECA2 también se expresa en células de tejidos extrapulmonares: endotelio, corazón, riñones e intestino, por lo que la infección por SARS-CoV-2 puede causar insuficiencia multiorgánica en casos graves. ${ }^{21}$

Posterior al ingreso del virus a la célula huésped, el genoma de ARN viral es liberado en el citoplasma celular, que se une al ribosoma de la célula huésped por su tapa metilada 5' y su cola poliadenilada $3^{1} .{ }^{10,19} \mathrm{El}$ ribosoma de la célula huésped traduce una poliproteína larga a partir del genoma del virus, posteriormente, esta poliproteína se escinde en múltiples proteínas no estructurales, que se unen para formar un complejo de múltiples proteínas Ilamado ARN polimerasa dependiente de ARN, que sintetiza por replicación el ARN genómico de sentido positivo para la progenie viral y por transcripción el ARN subgenómico de sentido positivo o ARN mensajero. Los ribosomas de la célula huésped traducen los ARN mensajeros a las diferentes proteínas estructurales y a una serie de proteínas accesorias dentro del retículo endoplásmico. Luego, las proteínas estructurales virales (S, E y M) se combinan con la nucleocápside mediante interacciones proteína-proteína para, finalmente, liberar de la célula huésped los virus de la progenie. ${ }^{10,19,24}$

\section{REFERENCIAS}

1. Lim YX, et al. Human Coronaviruses: A review of virushost interactions. Diseases. 2016; 4 (3): 26. doi:10.3390/ diseases 4030026.

2. Cui J, et al. Origin and evolution of pathogenic coronaviruses. Nat Rev Microbiol. 2019; 17 (3): 181-92. doi:10.1038/ s41579-018-0118-9.

3. Zhu N, et al. A novel coronavirus from patients with pneumonia in China, 2019. N Engl J Med. 2020; 382(8): 727-33. doi:10.1056/NEJMoa2001017.

4. Huang $C$, et al. Clinical features of patients infected with 2019 novel coronavirus in Wuhan, China. Lancet. 2020; 395 (10223): 497-506. doi:10.1016/S0140-6736(20)30183-5.

5. Lv M, et al. Coronavirus disease (COVID-19): a scoping review. Euro Surveill. 2020; 25 (15). https://doi. org/10.2807/1560-7917.ES.2020.25.15.2000125. 
6. Gorbalenya AE, et al. The species Severe acute respiratory syndrome-related coronavirus: classifying 2019-nCoV and naming it SARS-CoV-2. Nat Microbiol. 2020; 5 (4): 536-44. doi:10.1038/s41564-020-0695-z

7. Lu R, et al. Genomic characterization and epidemiology of 2019 novel. coronavirus: implications for virus origins and receptor binding. Lancet 2020; 395 (10224): 565-74. doi:10.1016/S0140-6736(20)30251-8.

8. Zhou P, et al. A pneumonia outbreak associated with a new coronavirus of probable bat origin. Nature 2020; 579 (7798): 270-73. doi:10.1038/s41586-020-2012-7.

9. Tang $X$, et al. On the origin and continuing evolution of SARS-CoV-2. Natl Sci Rev. 2020: nwaa036. doi:10.1093/nsr/ nwaa036.

10. Acter $\mathrm{T}$, et al. Evolution of severe acute respiratory syndrome coronavirus 2 (SARS-CoV-2) as coronavirus disease 2019 (COVID-19) pandemic: A global health emergency. Sci Total Environ. 2020; 730: 138996. doi:10.1016/j.scitotenv.2020.138996.

11. Wong $\mathrm{MC}$, et al. Evidence of recombination in coronaviruses implicating pangolin origins of nCoV-2019. bioRxiv. 2020 [preprint]. doi:10.1101/2020.02.07.939207.

12. Lam TT, et al. Identifying SARS-CoV-2 related coronaviruses in Malayan pangolins. Nature. 2020; 10.1038/s41586-0202169-0. doi:10.1038/s41586-020-2169-0.

13. Liu P, et al. Viral Metagenomics Revealed Sendai Virus and Coronavirus Infection of Malayan Pangolins (Manis javanica). Viruses. 2019; 11 (11): 979. doi:10.3390/v11110979

14. Xiao K, et al. Isolation and characterization of 2019-nCoV-like Coronavirus from Malayan Pangolins. bioRxiv. 2020 [preprint]. doi:10.1101/2020.02.17.951335

15. Prasad $\mathrm{S}$, et al. Transmission electron microscopy imaging of SARS-CoV-2. Indian J Med Res. 2020; 151 (2, 3): 241-43. doi:10.4103/ijmr.IJMR_577_20
16. Cascella $\mathrm{M}$, et al. Features, evaluation and treatment coronavirus (COVID-19) [Actualizado 2020 Abril 6]. En: StatPearls [Internet]. Treasure Island (FL): StatPearls; 2020. https://www.ncbi.nlm.nih.gov/books/NBK554776/

17. National Institute of Allergy and Infectious Diseases. New Images of Novel Coronavirus SARS-CoV-2. [Actualizado 2020 Febrero 13] Publicado 2020. https://www.niaid.nih. gov/news-events/novel-coronavirus-sarscov2-images.

18. Phan T. Novel coronavirus: From discovery to clinical diagnostics. Infect Genet Evol. 2020; 79: 104211. doi:10.1016/j. meegid.2020.104211

19. Lundstrom K. Coronavirus pandemic-therapy and vaccines. Biomedicines. 2020; 8 (5): E109. doi:10.3390/biomedicines8050109

20. Wrapp D, et al. Cryo-EM structure of the 2019-nCoV spike in the prefusion conformation. Science. 2020; 367 (6483): 1260-63. doi:10.1126/science.abb2507

21. Zhang $\mathrm{H}$, et al. Angiotensin-converting enzyme 2 (ACE2) as a SARS-CoV-2 receptor: molecular mechanisms and potential therapeutic target. Intensive Care Med. 2020; 46 (4): 586-90. doi:10.1007/s00134-020-05985-9

22. Korber B, et al. Spike mutation pipeline reveals the emergence of a more transmissible form of SARS-CoV-2. bioRxiv. 2020 [preprint]. doi:10.1101/2020.04.29.069054

23. Wan $\mathrm{Y}$, et al. Receptor recognition by the novel coronavirus from wuhan: an analysis based on decade-long structural studies of SARS Coronavirus. J Virol. 2020; 94 (7): e0012720. doi:10.1128/JVI.00127-20

24. Letko $M$, et al. Functional assessment of cell entry and receptor usage for SARS-CoV-2 and other lineage $B$ betacoronaviruses. Nat Microbiol. 2020; 5 (4): 562-69. doi:10.1038/s41564-020-0688-y 